\title{
Information Technology Sustainability Problems and Possible Solutions
}

\author{
Rudite CEVERE, Aleksandrs GAILUMS \\ Department of Computer Systems, Latvia University of Agriculture, Liela iela 2, LV3001, \\ Jelgava, Latvia \\ rudite.cevere@llu.lv, aleksandrs.gailumsellu.lv
}

\begin{abstract}
Problems of sustainable development today are identified and tried to solve in all fields of life. In this respect information technologies play a specific role. Many studies have been devoted to analysis of information technology (ICT) as tools for sustainable development. Different contributions and threats posed by ICT to sustainable development are discussed. However, methodological and legislative base of software development is not sufficiently researched from the perspective of sustainable development of information technologies. This paper presents literature review of conference and journal articles and materials of international projects on the topic of different ICT roles in sustainable development. The review shows the lack of regulatory framework analysis of information technologies. This analysis is done in separate part of the present paper. We found and analysed weaknesses of evolution of software development methods which put marketing considerations in the first plan. On the basis of the done analysis we discuss possible future work to put sustainable foundations to information technology knowledge from the very beginning of ICT specialists training.
\end{abstract}

Keywords: Information and communication technology; Sustainable development; Software engineering.

\section{Introduction}

Industrial, scientific and technological progress, as well as the world's population today has led to a situation where ensuring sustainable development may be the only chance of survival. Sustainable development issues are identified and attempts to find solution can be seen in almost all sectors. Information and communication technologies (ICT or IT for short) are set of knowledge, methods, techniques and technical equipment that by means of computer and communications provide acquisition, storage and distribution of any data. Therefore they provide tools, which can be used to address the problems of interest in all sectors. ICT also plays an important role from the very beginning of the sustainable development activities.

All over the world a wealth of information is now being published on various aspects of sustainable development, including relations between the ICT and sustainability problems. Only a small part of the publications has been reviewed in this paper based on such centralized sources of information as International Institute for Sustainable Development (IISD), Internet Society, Higher Education Academy, and Institute for Computational Sustainability. Discussions on the role of ICT in ensuring sustainable development can be found in many other publications. 
The International Institute for Sustainable Development (IISD) is one of the most important centres for the exchange of information on ICT for sustainability (https://www.iisd.org). IISD is an independent, non-profit organization that provides practical solutions to the challenge of integrating environmental and social priorities with economic development. IISD mission is to promote human development and environmental sustainability through innovative research, communication and partnerships. A variety of approaches are seen in these studies.

\section{Different ICT roles in sustainable development}

Paul Mobbs in his practical guide to sustainable IT (Mobbs, 2012) looks at the use of IT from the viewpoint of the information which the system manipulates. The guide's themes of sustainable IT are based on information "flower", containing software, hardware, resources, disposal, care, storage, and networks. Each petal represents one aspect related to the sustainable use of IT. Sustainability issues of information technology physical impact on the environment are marked, as well as sustainability requirements in relation to IT systems themselves. The author points out that the development and use of these systems is affecting the global ecosystem that sustains life on earth. For example, many observations prove that the impact of information systems and telecommunications has as great an effect on environment as the air transport system. Assessing the impact of ICT on sustainability doesn't include only environmental pollution. We have to look more widely including view of how we design, maintain and operate the information systems that support our everyday life. It should be done in a way which considers not only the impact on the planet today, but also how we develop, use and preserve information resources for ourselves and for future of mankind. It means that people must learn to plan use of information systems to maximize material efficiency while minimizing their environmental impact by making IT tools more sustainable. It is addressed to issue of how to know when equipment has reached the end of its useful life and how to dispose of it safely, as well as how information technology devices can be upgraded or recycled and given a new opportunity of functioning.

\subsection{Internet and sustainable development}

One of the topics maintained by IISD is Internet and Technology. It is noted that trends of development of internet services suggest a future where one will be able to connect to the internet anywhere and at any time, as well as a future where the internet will be the foundation for all information and communication exchanges.

The report edited by David Souter and Don MacLean explores the changing relationship between ICT, the internet and sustainable development. The report is the result of a series of dialogues held by the International Institute for Sustainable Development during 2012 (Souter and MacLean, Eds., 2012).

David Souter in his discussion paper (Souter, 2012) talks about two main issues of critical importance for today's world: essence of sustainability and the changes that are resulting from extensive use of information and communications technologies and especially the internet. The viewpoint of this paper is concentrated to question "How far and in what ways do we need to change our understanding of sustainability in the light of the information and communications revolution?" Main changes in the ICT environment 
since first World Summit on the Information Society are related to reach, adoption and usage, quality and variety of services. Together with many benefits the ICT sector itself has become a significant source of damage to the environment, through both electronic waste and greenhouse gas emissions. The valuable analytical framework widely used for analyzation of the impacts of ICT on sustainability is described. It discusses assumption that sustainability in the information age means something different from what it meant in the late industrial age. Positive and negative effects of ICT on the sustainability are considered and the necessity to carry out a wide range of international discussions on these aspects is pointed out.

Robin Mansell in his discussion paper notices that "ICT innovation is a complex system of interactions involving all areas of production and consumption and civil society activities. The trajectory of ICT innovation is neither "natural" nor predetermined. It emerges from self-fulfilling visions based on the decisions of multiple actors and their expectations about the future" (Mansell, 2012).

A central theme in the dialogue about internet governance usually has been the management of internet resources on a technical level. Main attention is paid to the domain names systems and IP address allocation mechanisms, the underlying technical standards and protocols have been developed. But the issues necessary to be solved to ensure extensive use of the internet extend into the areas of politics, security, intellectual property rights, economic issues and many others. That means that internet policy development and governance requires more broad-based collaboration and participation than is currently happening (Akoh et al., 2012).

There is a wide range of stakeholders connected to the internet: the private sector, the public sector, end users, and academics. According to it wide and many-sided is their range of interests. One of them has invested in the infrastructure, the others has responsibility to safeguard the interests and rights of citizen. Users depend on the internet in different way and it affects their quality of life and communications with family and friends. Interests of academics lie in education and research. It is therefore important to have an approach to policies that recognize and support everyone's interests, needs and rights.

The authors offered a toolkit 'to the policy practitioner and stakeholders interested in internet public policy using a structured and systematic approach that involves broad sectors of society. The first part of their publication is an overview of the concept of internet public policy process viewed through a multi-stakeholder approach. The second part is a description of the toolkit and a step-by-step guide of how policy practitioners can use them to drive a multi-stakeholder internet public policy process in their countries, regions or provinces.

The Internet Society (ISOC) in its briefing related to the United Nations discussion on the Sustainable Development Goals describes the internet's potential and identifies priorities for action (WEB (e), 2015).

Seventeen proposed Sustainable Development Goals, and 169 targets, have been developed through an intergovernmental Open Working Group (OWG) of the United Nations. One of the proposed targets calls for significantly increased access to information and communications technology, and ICT are specifically mentioned in three other targets The Internet Society is concerned, however, that the internet's importance has not been sufficiently recognized, and that more must be done to integrate the Information Society and sustainable development agendas. ISOC believes that more attention should be paid to the internet's catalytic role in meeting information needs and 
facilitating development, particularly in sectors such as agriculture, health, education and enterprise.

Three things in particular will be crucial to the internet's success: multi-stakeholder participation, open, universal, interoperable standards, and collaborative security approach.

ICT will have even greater impact on development implementation and outcomes over the next fifteen years. The Internet Society believes this will be especially important in five areas: sustainable development policy, implementing sustainable development, monitoring sustainable development, leveraging big data for development, and sustainable multi-stakeholder approaches to developments.

\subsection{Impact of ICT to sustainable development}

Looking at the importance of ICT tools for the sustainability, much attention is paid to the concerns of harmful effects of ICT sector own (St. Arnaud, 2012). Most of green IT initiatives have focused on energy efficiency strategies by reducing the electrical energy consumption of devices such as computers, printers and networks. Despite some simple achievements in energy efficiency, the direct energy consumption and carbon dioxide emissions of the ICT sector continue to increase. The ICT sector already represents 8 per cent of global electricity consumption and this is predicted to grow to 10-12 per cent of all electrical consumption in the next decade. Future broadbandinternet alone is expected to consume 5 per cent of all electricity. Weak successes of ICT industries to reduce energy intensity are explained with ineffective measures to stimulate it. Furthermore, the global demand for ICT tools is growing. It is high time now to look seriously at how the ICT sector itself can adapt to a warming planet as well as assist other sectors of society in their adaptation strategies. 2012).

Graham Vickery describes three levels of ICT impact on the environment (Vickery,

Direct impacts of ICT on the environment ("first-order effects") refer to positive and negative impacts due directly to ICT products and services and related processes. Direct environmental impacts of ICT products come from ICT manufacturing and services producing firms and related producers of intermediate goods, and from final consumers and users of ICT.

ICT affect how other products are designed, produced, consumed, used and disposed of. Enabling impacts of ICT ("second-order effects") come from ICT applications that reduce environmental impacts across economic and social activities outside of the ICTproducing sector and straightforward ICT applications. ICT products can affect the impact on the environment of other products in four main ways: optimization (ICT can reduce another product's environmental impact), dematerialization and substitution: (physical products and processes can be replaced by digital ones), induction (ICT products induce increased demand for other products), and degradation (ICT devices embedded in non-ICT products lead to difficulties in disposal management).

Systemic impacts of ICT on the environment ("third-order effects") are included in behaviour and behavioural change. ICT applications have systemic impacts in a number of ways, including providing and disclosing information, enabling dynamic pricing, and changing technologies impacting consumer and user behaviour. The author concludes that initiatives of governments have largely concentrated on greening ICT rather than solving global warming and environmental degradation problems through the use of ICT. 
Two essential issues form the basis of current thinking about the development of global economies and societies are defined in (Souter et al., 2010). They are the challenge of environmental sustainability, and the potential of information and communications technology. The paper describes the relationship between these two critical dimensions of change in global policy in the early years of the twenty-first century, and their impact on global development. A valuable framework for analysing impacts on sustainability is described. In the core of this framework is a simple matrix:

\begin{tabular}{|l|l|l|l|}
\hline & 1 st order effects & 2nd order effects & 3rd order effects \\
\hline Economic sustainability & & & \\
\hline Social sustainability & & & \\
\hline Environmental sustainability & & & \\
\hline
\end{tabular}

In this matrix, "first order effects" refer to the immediate and direct effects of a particular factor on sustainability (in this case of ICT); "second order effects" refer to indirect impacts; and "third order effects" refer to societal impacts taking place over a longer period of time.

The matrix can be applied to the interface between any sector or policy domain and sustainable development, but is particularly helpful to understanding the impact of ICT on sustainable development.

The first order effects of ICT on climate change are both strong and negative.

The second order effects of ICT on climate change are generally considered first order effects. These fall into two main categories. First, ICT can be used to increase the efficiency of other industries, most notably power generation and distribution and logistics in sectors such as transport. The second category of second order effects is more directly related to wider access and usage. This is the impact of dematerialization that allows the displacement of physical with virtual activity. Third order effects of ICT on climate change are those that result or will result from the kind of large scale behavioural and social structural changes. Innovations such as social networking, homeworking and home-shopping do not just have immediate direct impacts on individual behaviour. They also have longer term direct and indirect impacts on the ways in which societies and organizations work.

ICT may have systemic effects within society as a whole related in changes of the behaviours and values of individuals who are citizens and consumers. These effects may be positive or negative from the perspective of environmental sustainability.

The authors came to the conclusion that what happens in the ICT and internet contexts, in short, will affect what is sustainable and what can be done about sustainability in future.

The study described in (Rivera and Kurnia, 2015) adopts the four roles of IT/IS (Automation, Informating, Transformation, and Infrastructure) proposed by referenced former publications and the three dimensions (Economic, Environmental, Social). By implementing automation, ICT have been used in many organizations to replace manual business processes with computerize application systems. Informating tasks help organizations produce useful information from the various data captured by different tools from the different sources. Through the transformation tools, ICT can be used to modify business operations and introduce significant changes into the way organizations carry on their business process. The infrastructure task includes maintenance of hardware, software and network components to support ICT services. 
Don MacLean in his commentary (MacLean, 2013) points to the lack of effectiveness of the current Sustainable Development international conference in relation to ICT commitment to sustainability problems. Author notes six important positive moments in the ICT contribution to sustainability and five serious harms. In order to promote the positive moments and to reduce the threat posed by ICT as the key is marked: countering cyber-crime and ensuring cyber-security, protecting privacy, managing the critical resources, ensuring adequate and continuous investment in the telecommunications infrastructures, and ensuring that access to these infrastructures and the services is open, accessible, and affordable. The second important issue is to support the development of policies, programs, and processes aimed to sustainability through the application and use of ICT and the internet. To become meaningful guides to furthering the integration of the internet and ICT into sustainable development policy, the Sustainable Development Goals must include goals related to the development of people's digital capabilities and digital literacies in each of these areas. Some of the work needed to incorporate sustainability principles in ICT governance has already begun. Technical standards are being developed at the ITU and in other forums to increase the energy efficiency of ICT equipment, networks, and devices, and to reduce the greenhouse gas emissions and ewaste generated by the sector.

\subsection{Information and communication technologies and society}

Contemporary assessment of the situation shows that development of information technology is far surpassed other forms of modern infrastructure (Finnegan and Cyr, 2012). Practically it means that policy and development programs are not sufficiently able to keep up with technology changes. All stakeholders should discuss the opportunities and threats posed by technology, otherwise ICT may contribute unsustainable development. Possible themes of periodical discussion are given in (MacLean et al., 2012).

International studies and discussions on the role of ICT development are ongoing. In 2013 a Global Connectivity Group for Sustainable Development Discussion Forum published a manifesto to UNESCO conference Towards Knowledge Societies for Peace and Sustainable Development (Souter et al., 2013). It once again deals with three main issues: (1) the impact of ICT and the internet on economy and society, politics and culture during the past decade; (2) the relationship between ICT and conflict; and (3) the risks posed and opportunities arising for sustainable development from constantly evolving information and communication technologies. Computers are linked with modern military hardware like flying drone aircrafts and targeting precision weaponry. Nowadays terrorists and rebel armies use mobile telephony and the internet instead of radio communications that has been actually during past decades. ICT and the internet is used in the preparation of the conflict, as well as for its ensuring. The potential role of the internet in conflict is an increasing priority in intergovernmental discussions over cyber security.

In the report, prepared for the UNESCO WSIS+10 Conference Robin Mansell and Gaëtan Tremblay (Mansell and Tremblay, 2013) focus on the importance of freedom of expression and information, universal access to information and knowledge, quality education for all, and respect for linguistic and cultural diversity.

A set of guidelines for UNESCO's strategy towards knowledge societies with clear priorities in each of the areas were proposed. Among others they include such issues as 
prioritizing learning processes, access to information and knowledge, coordinated action for accessing and linking information, and balancing rights of access to information.

One of the IISD projects written and published at the time around the second Earth Summit (Rio+20, in 2012) (Souter and MacLean, 2012) summarized and reviewed the relationship between information and communication technologies (ICT), based on the issue how far and in what ways do we need to change our understanding of sustainability in the light of the information and communication revolution. The main conclusions of the study defined challenges addressed to governments, businesses and other stakeholders in both ICT and sustainability scope that are central to the interaction between ICT and sustainability. They are mitigation of the environmental impact of ICT; maximization of their potential contribution to environmental adaptation and sustainable economic growth, and understanding of the long-term changes that are inherent in an evolving Information Society. A need for active international discussions on internet and sustainability is marked as very significant. It should be more fruitful than that which currently takes place.

Four important messages are given in the 2015 edition of The Global Information Technology Report (Dutta et al., Eds., 2015). The ICT tools have the potential of transforming economies and societies. This has been achieved in only one part of the world thanks largely to the development of the internet. In other parts higher level of preparedness and better infrastructure and access are needed. At the same time digital divides exist even within the most advanced countries.

\subsection{Evaluation of ICT and Internet}

Review of a wide range of literature (more than 90 sources) is given in (Raghupathi and $\mathrm{Wu}, 2013)$, in which the authors investigate the strategic association between information and communication technologies (ICT) and sustainability development indicators using empirical data. The framework to characterize the association between ICT and country sustainability contains Explanatory Variables: ICT accessibility, ICT affordability and ICT quality; institutional efficiency and sustainability, and ICT applications. The Control Variable is country income level. The Dependent Variables are environment, energy production and consumption, economic development, transportation and education.

The purpose of this exploration is to examine the association between ICT and sustainability at the macro level. The Global e-Sustainability Initiative (GeSI) considers extending the influence of ICT to all aspects of socio-economic development and applying these technologies to both rich and poor countries in order to achieve the strategic principle of sustainable development across the globe.

A separate group of researches is related to ICT and internet evaluation.

Different research direction is associated to a network assessment. IISD publication (Ryan and Creech, 2008) describes an attempt to use social network analysis methods for assessing structure and quality of a network. The paper includes an overview of the literature on social network analysis and network governance, and methodology used in experimental assessment of the IISD network. The report of the Organisation for Economic Co-operation and Development (OECD) (WEB (b), 2009) suggests a conceptual framework for the new statistical field "ICT and the environment" based on an existing OECD framework for information society statistics.

In 1996 Kestemont (Kestemont and Hecq, 1996) evaluated the role of IT in information processing as a way to improve the decision making process. Therefore, 
improving information technology should make the results to be more reliable and less risky. It would accelerate the way of making reliable information from ground measurements, and allow more transparency in the modelling processes. The role of information technology in decision-making process is being developed also at a later stage.

Hameed Ahmed Khan (Khan) notes that information technology helps efficiently find and transport information to the decision makers in a useful, readable form. Looking at the spheres of application of ICT, he also focuses on ICT as a translation tool, the meta data production principles and the way how should the Developing countries adopt the new information Technology.

\subsection{Information technologies and education}

Looking at the role of ICT in today's society, the relations of information technology with education has been described in different contexts. Many studies have been devoted to ICT role in education. Lesly Paas in his paper (Paas, 2008) describes brief history of the use of ICT in education and considers three main questions: why do ICT need to be considered as a critical tool in education for sustainable development, what ICT are currently being used by educators and learners, and what can we expect to see in the near future.

For the use of ICT is essential not only to find the methods of use, but also to be able to assess the quality of the results. Special significance it gets in the development of global information society. The initiatives that were taken to give ICT a place in education have resulted in a need to monitor these developments, using reliable and valid indicators. Data to support the perceived benefits from ICT are limited and evidence of effective impact is elusive or even debatable. These findings highlighted various knowledge gaps and underscored the need for internationally accepted standards, methodologies and indicators to better measure the real benefits of ICT in education. The UNESCO Institute for Statistics developed the manual that presents a more comprehensive set of internationally comparable indicators on the use of ICT in education, along with standardized definitions of key concepts, detailed measurement specifications and practical guidance on appropriate interpretation of the indicators (WEB (a), 2009).

Another view point on interaction between ICT and education is related to inclusion of sustainable development issues in the education system programs. Roger Penlington and Simon Steiner describe an Introduction to Sustainable Development in the Engineering Curriculum (Penlington and Steiner, 2010); WEB (d), 2014).

Rogers-Estable in her paper (Rogers-Estable, 2011) describes some recent technologies and applications that contribute to the education for sustainability (ESD) movement, along with examples of their uses. Technology is and will be a major player in the ESD process that helps disseminate information via distance education technologies, the internet and social applications. However, that technology is not the cure-all for world problems.

\subsection{Sustainability in software engineering requirements}

For ICT connection with sustainability issues important direction of the work is associated with software engineering requirements. Martin Mahaux, Patrick Heymans, 
and Germain Saval in their publications underline that influence on the sustainability largely depends on decisions made during Requirements Engineering (RE) (Saval et al., 2013); Mahaux and Canon, 2012; Mahaux et al., 2012). Analysis of literature at a time when they started their project showed that this issue is hardly overlooked. Their research dealt with the goals to understand how sustainability requirements can be discovered, what approaches already exist to define them and what limitations they have.

Some years later more and more papers start appearing, related to a deeper research about the thematic, including Sustainability Aspects in Software Engineering. Sustainability is not supported by traditional software engineering methods. A description of the aspects of sustainability in software engineering is given in (Penzenstadler, 2013)

The specific studies in this direction are associated with DFG EnviroSiSE project and National Science Foundation Grant. The aim of this project was to support the scope of sustainability within different processes of the software lifecycle, with a focus on requirements engineering (RE) and quality assurance (QA). The goal was to develop a Non Functional Requirement Framework for Sustainability as the basis upon which requirements engineers can categorize various sustainability requirements gathered for the software system to be built. Besides it the intent was to develop components for two standards: IEEE 830 Recommended Practice for Software Requirements Specification, and ISO 9126-1 Software engineering - Product quality.

The Software Engineering for Sustainability (SE4S) research project has developed a number of contributions with regard to how software engineers can include sustainability as major objective into software systems development. The future work is related to provision a research roadmap for software engineers towards sustainability (Penzenstadler, 2015) and developing the approach of how green requirements may be conducted within the scope of general purpose requirements engineering (Penzenstadler, 2016).

As the EnviroSiSE funding has run out and the website of the project is no longer updated, the main information exchange site on these issues is the site maintained by Dr. Birgit Penzenstadler (http://birgit.penzenstadler.de/index.html\#) where a list of projects, talks, activities, and different kind of publications can be found.

\section{Review summary}

Accomplished literature review shows that new opportunities given by the ICT are described in almost all areas of life. At the same time, this review shows that information technology commitments to sustainable development are viewed either from a narrow point of view, or in very general terms, mentioning all the possible areas of impact. As a result, it is difficult to distinguish the main ICT positive and negative effects, and typical forms of influence. From the point of view of favourable effect most frequently mentioned are the following:

- ICT provides new technologies, methods and tools for the development of scientific research. With help of ICT it becomes possible to handle increasing amounts of data using new data processing and visualization capabilities. For example, ICT provides opportunities to model, manage and control the ecosystem processes at all levels, ICT also have significant potential for climate change adaptation, particularly in data collection, analysis and dissemination of information on weather, land and water resources. 
- In economic development ICT and particularly the internet provides a basic platform for the growth of digital economy, in which production, distribution and consumption depend on broadband access and services. Producers have developed more intensive and more interactive relationships with supplier which helps innovators and entrepreneurs create green jobs throughout the economy and sustainable businesses. Positive direct effects in terms of economic are connected with creation of new jobs. ICT methods and tools improve efficiency in manufacturing and trade, and industrial production is using much higher levels of automation and has become quite widely globalized. Financial markets have been transformed by electronic trading. This has made access to financial markets much more open.

- $\quad$ ICT enable vastly more efficient uses of energy and material resources through the development of "smart" energy, transportation, building, manufacturing, water, agricultural, and resource management systems. "Smart systems" also help to achieve reductions in carbon emissions.

- Virtualization can eliminate wasteful network equipment, reducing energy and floor space. The ICT sector's own impact on environmental protection is already substantial and growing in importance. It's certain and rapidly growing contribution is particularly important to waste and greenhouse gas emissions.

- Information technology enables teams of employees to work on projects collectively from diverse locations. Employers in areas of high labour costs outsource development and management to contractors in areas of lower labour cost. ICT have enabled major changes in the ways that businesses are run. Most administrative functions have become computerized.

- The ICT sector itself has become a significant part of many economics.

- Technology and new software have created an environment full of online learning opportunities, both formal and non-formal.

- $\quad$ ICT is promoting lifestyle change, support the transformation of organizations and institutions in the private and public sectors through the dematerialization of products and services and the virtualization of processes and relationships. Homeworking and telecommuting are gradually becoming widespread, with increasingly significant impacts on family structure and working hours. Telework can reduce not only automobile travel but overall energy used by reducing the amount of dedicated office space. The internet enabled anyone with basic literacy skills and the right equipment to access information and to interact directly with other users in any part of the world. It has a large influence in domestic and small business environments, and therefore direct effect to social equity.

- The internet has altered and continues to alter decision-making capabilities, including more inclusive participation in governance. The internet alters relationships between governments and citizens.

- The internet and social media provide young people with a range of benefits, and opportunities to empower themselves in a variety of ways. Young people can maintain social connections and support networks that otherwise wouldn't be possible, and can access more information than ever before. The communities and social interactions young people form online can be invaluable for bolstering and developing young people's self-confidence and social skills. For individuals using the internet can be a social opportunity to meet and interact with new people online. 
- $\quad$ ICT is a very powerful tool for enabling people with similar problems, e.g., health problems or interests like politics, films, music, to form meaningful online communities.

All of these new opportunities gives or may give an impact that is positive in one or another way, but not always this effect is promoting sustainability. The Internet Society encourages paying more attention to the relationship between the internet and sustainable development to ensure that potential gains are maximized.

Along with new opportunities provided by the development of ICT the new threats become visible. The more common risk situations are the following.

- The loss of jobs in sectors undermined by internet-enabled businesses.

- Large amounts of waste generated by the sector; short life cycle of ICT devices; rapidly growing greenhouse gas emissions that result from equipment manufacturing, network operations, data centres and the use of an ever-growing range of terminal devices by an ever-growing consumer base.

- The problems with highly complex mixtures of materials in e-waste, and recovering the substances they contain without causing any toxic pollution. Even when the best reclamation technology is used, and high recycling rates are achieved, toxic waste streams requiring safe long-term disposal are still produced.

- The fastest growing energy use in the ICT sector, following the rapid development of information technology.

- Increasing of volatility of financial market in the result of their transformation. This has destabilized these markets, leading to higher levels of risk, and giving greater economic power to speculators at the expense of economic planners and business managers.

- Undermining the boundaries between work and leisure, and altering relationships between employers and employees in the result of continuous availability online and through mobile phones.

- New security challenges that has risen from the internet for both governments and citizens, from the threat of disruption to the internet itself to new forms of criminality (cybercrime). A range of questions arise about the relationship between security, surveillance, rights and privacy.

- The risk of facilitating antisocial behaviour that raises from several aspects of ICT. Using IT can be addicting and a form of social escapism.

- Possible formation of digital divide. If only a portion of society has access to information tools such as online learning, electronic health records, and egovernment services, then society will move in direction of greater inequality.

- Creation of new structural problems from an information quality standpoint due to increase of computer-mediated communication, driven by dramatically lowered cost.

According to a comprehensive nature of the sustainable development, published topics, which analyses these problems in relation with information technologies are very diverse. Certain issues of classification are included in most of them, but they are looking at this relationship in a context of the particular paper, such as the role of ICT in the development of society, education, environmental pollution control, etc. Describing the new opportunities offered by ICT the assessment of their impact on sustainability is not always given, as well as the positive and negative effects are not evaluated. If it is 
given then it is only in relation to the dominant point of view of a particular paper. A development of a single list of positive and negative impacts of ICT on sustainable development is not yet found.

Short list of new opportunities provided by ICT and generated threats gathered from the reviewed literature is given in Table 1.

Table 1. Contributions and Threats of ICT

\begin{tabular}{|c|c|c|c|}
\hline No & Contributions & No & Threats \\
\hline 1. & Creation of new jobs & 1. & Natural pollution formation \\
\hline 2. & Economic stimulation & 2. & Increase in energy consumption \\
\hline 3. & Waste reduction & 3. & E-waste generation \\
\hline 4. & Power saving & 4. & Access to information \\
\hline 5. & Work automation & 5. & Information quality drop \\
\hline 6. & Access to information & 6. & Formation of the digital divide \\
\hline 7. & Growth of educational opportunities & 7. & Job losses \\
\hline 8. & Communication options & 8. & Security issues \\
\hline 9. & Lifestyle changes & 9. & Health problems \\
\hline 10. & Facilitation of social benefits & & \\
\hline 11. & Development of scientific research & & \\
\hline 12. & Security problems solving & & \\
\hline 13. & Carbon emissions reduction & & \\
\hline 14. & Financial market changing & & \\
\hline 15. & $\begin{array}{l}\text { Formation of new field of science and } \\
\text { industry (ICT) }\end{array}$ & & \\
\hline 16. & Changing of business forms & & \\
\hline 1 & Environmental protection promotion & & \\
\hline 18 & Decision-making process improvement & & \\
\hline
\end{tabular}

Looking at ensuring sustainability of the information technology, a focus is on hardware issues. Inclusion of sustainable requirements in the software requirements definition also has been developed. However, it is not discussed in more detail how information technology methodological and regulatory framework impact on information technology sustainability. This aspect today can be characterized by the increase of commercialization, rapid and often insufficiently justified introduction of new terminology, as well as growth of regulatory documents including software engineering standards.

\section{Development of normative base of information technology}

Development of hardware and software tools of information technology and expansion of fields of their application bring new tools and methods for software product lifecycle support. It also creates new risks to the sustainability of information technology itself because constantly growing amount of information does not allow acquiring it up to such an extent that it can be used successfully.

In discussions of the role of ICT in sustainable development the necessity to develop common standards is often mentioned. Usually, the scope of standards is related to the ICT contribution in reducing damage to the environment, as well as to necessity for 
single internet international realization. Development of general information technology standards in this context is not discussed. However, they have an important role in the implementation of advanced development methods.

Several important software engineering standards contain parts in which the latest results of the development of theoretical methods and summary of good practice are described. Two particularly important areas in sense of theory development are software product quality assurance and testing standards. On the one hand, in these standards the latest achievements of the development of corresponding methodology are summarized. They present a high level overview of the activities that are recommended for software development. And unlike many other publications, these have been determined by international consensus rather than by one or two experts in the field. On the other hand, incorporation of the methods in the standards creates a powerful mechanism for their implementation in software development projects. Thus, for example, research projects related to software engineering and sustainability were developing the approach of how green requirements may be conducted within the scope of general purpose requirements engineering and putting forward a proposal of including components into software engineering standards (Penzenstadler, 2016).

The most important groups of software engineering standards, which determine software quality assurance key elements, are standards for software lifecycle processes, security, testing and quality management.

Standards are developed also for the description of many other areas of ICT. Currently IEEE Standards Association catalogue presents more than 990 names of standards and ISO standard catalogue more than 159 names which contains keywords "software engineering". That means that the total number of the industry standards is huge. It gathers a wide and diverse knowledge that is subject to specific conditions of use and skills.

In recent years' new versions have been developed for the most important software engineering standards, and new versions have become significantly bigger and more complex. Together with the development of new ideas, it has an impact on the sustainability of information technology.

\subsection{Software lifecycle processes}

The main standard that describes software life cycle is ISO/IEC 12207. Instead of the industry name "Software Engineering" in the new version of standard 12207 "Systems and software engineering" is used. Better alignment of International Standards ISO/IEC 12207 and ISO/IEC 15288, and facilitating of their joint use have been defined as the purpose of development of new version. In the result of this merger the volume of the Standard significantly increased (see Table 2).

Table 2. Volume comparison of standard 12207 versions

\begin{tabular}{lll}
\hline Characteristic & $\mathbf{1 2 2 0 7 - 1 9 9 6}$ & $\mathbf{1 2 2 0 7 - 2 0 0 8}$ \\
\hline Number of pages & 57 & 138 \\
Defined processes & 17 & 43 \\
Defined activities & 74 & 126 \\
Defined tasks & 235 & 325 (untested number) \\
\hline
\end{tabular}


Work experience in the position of the company's leading quality manager showed that it is sufficient to develop process descriptions only for 14 processes. This was quite enough for development of "Product Realization section "of the ISO 9000 plus TickIT certified quality system and its successful maintenance since 2000. Tailoring of the new version of standard 12207 to needs of real projects would be much more labour intensive. There is no evidence that the result would have achieved a considerable improvement.

With evolution of software development methods, the tools and techniques used for the defined activities and processes are changing too. In recent decades, great changes have affected organizational processes that determine the sequence of separate activities and cooperation among them. The form of its implementation is a software (or software development) life cycle models. Together with new lifecycle models a new terminology appears which talks about the software development processes and roles.

Incremental, evolutionary and spiral models are formed from the classical waterfall model as it evolves. Typical project staff roles in these models are the project manager, systems analyst, programmer, and tester.

The next stage of development is connected with creation of rapid development methods (Rapid Application Development). One of the best known is Dynamic System Development Method. These methods focus on faster creation of operational software, and a developer's team includes roles of project manager, technical coordinator (chief designer), group manager, developer and tester. Active inclusion of customer representatives in the development team is essential, and their roles are Executive Sponsor, Visionary, Ambassador User and Advisor User.

With appearance of Agile methods terminology is changing even more. Most popular of Agile methods is known as Scrum, and its project team consists of product owner, scrum master, and development team. A prioritized list of ideas for the product is called a product backlog, and small pieces of the product are built incrementally in a series of short time periods called sprints. Other well-known Agile methods are XP (Extreme programming), Kanban, Crystal, which also came with a new terminology that differs from standard language. That requires from developers to acquire not only the new methods but also to speak about old activities in new terminology.

\subsection{New requirements for software testing}

Second substantially revised group of standards is testing standards that describe a very important basic process of software development. Testing process has also a crucial role in software product quality assurance. During the development of new version, the volume of this standard has also increased.

The number of parts in testing standard has risen from 3 to 6 . The content of testing documentation standard has changed significantly. As shown in Table 3 instead of current 8 types of testing documents now 16 types have been defined.

Taking into account the fact that in all software development projects it is not necessary to prepare all forms of the test documentation, the greater number of possible documents may result in additional time-consuming tailoring. 
Table 3. Changes in test documentation types

\begin{tabular}{llll}
\hline No. & ANSI/IEEE Stud 829-1998 & No. & ISO/IEC/IEEE 29119 \\
\hline 1. & Test Plan & & Organizational Test Process Documentation: \\
2. & Test Design Specification & 1. & - Test Policy \\
3. & Test Case Specification & 2. & - Organizational Test Strategy \\
4. & Test Procedure Specification & & Test Management Process Documentation: \\
5. & Test item transmittal report & 3. & - Test Plan (including a Test Strategy) \\
6. & Test Log & 4. & - Test Status Report \\
7. & Test incident report & 5. & - Test Completion Report \\
8. & Test summary report & & Dynamic Test Process Documentation: \\
& & 6. & - Test Design Specification \\
& & 7. & - Test Case Specification \\
& & 8. & - Test Procedure Specification \\
& 9. & - Test Data Requirements \\
& 10. & - Test Data Readiness Report \\
& 11. & - Test Environment Requirements \\
& 12. & - Test Environment Readiness Report \\
& 13. & - Actual Results \\
& 14. & - Test Result \\
& 15. & - Test Execution Log \\
& 16. & - Test Incident Report \\
\hline
\end{tabular}

\subsection{Development of software product quality models}

Other significantly revised software engineering standards are software product quality standards. A previous version of this group consisted of two standards for a total number of 10 parts. In the new version the SQuaRE series of standards consists of five divisions under the general title Systems and Software Quality Requirements and Evaluation (SQuaRE): Quality Management Division, Quality Model Division, Quality Measurement Division, Quality Requirements Division, and Quality Evaluation Division.

General goal of creating the SQuaRE set of International Standards was to move to a logically organized, enriched and unified series covering two main processes: software quality requirements specification and systems and software quality evaluation. SQuaRE includes Standards on quality model and measures, as well as on quality requirements and evaluation, it replaces the ISO/IEC 9126 series and the ISO/IEC 14598 series.

It should be noted that in the new version of the standard there is no significant changes in the recommended software product quality model form and its use. There is an attempt to increase the number of quality characteristics and change their classification.

\subsection{Latvian information technology industry legislation}

Analyzing the existing legislation and regulatory rules of Latvian ICT industry sector we can see that the range of documents of different levels is so wide, and the amount so large that it is impossible to compile a full list of all regulatory documents. On the one 
hand, it might not be necessary because the stakeholders in each individual case can identify the mandatory rules for themselves and overlook others. On the other hand, so there remains a risk that the same question in different applications is treated differently. In addition, during development of information systems, which realizes the various legal requirements, the situation can happen for the developers that different legislation is contradictory or incomplete. In development of information system for data processing in accordance with some regulatory requirements there may be cases that part of the data is not available because procedures of information storage and processing are not well defined in other regulatory documents. There are also situations when an information system starts to use the data accumulated in other IS, for example, a personal identification code, and this data turns out to be erroneous.

Information technology today is used in all industries. Consequently, regulations governing the acquisition, development and use of ICT tools and techniques have been developed also in different ministries and other state institutions. It happens that the documents of similar nature are being developed in a number of institutions. As a result, set of ICT regulatory and recommendatory documents will increase even more.

It demonstrates the need for comprehensive and timely cooperation in order to ensure the integrity of the information to be processed and to prevent failures and contradictions in legislation, and to prevent them in the future. In this respect, cooperation among all participants of the ICT sector has an important role.

Considering the global nature of information technology, Latvia must also comply with the European Union and international law, and to ensure cooperation with international information systems.

\section{Analysis and evaluation of normative base}

Although use of software engineering standards for software development projects is not compulsory, in practice it is quite common. The standards become mandatory in case when it is required by the laws, contracts or other legal obligations. During development of a project, the customer may require to include in the contract usage of certain standards. Mandatory compliance with standards is typical in cases when customers are public authorities.

The use of standards in software development requires from project team special training and knowledge acquisition. Usually in each standard the principles of tailoring have been explained. They say that within a document, the content of each section may be tailored to the particular application. In addition to tailoring the content, supplementary documents may be added to the basic set, additional sections may be added to any document, and additional content may be added to any section.

The nature of information technology sets that two completely identical developments are impossible. It dictates the need to acquire skills to adapt general requirements to the needs and terminology of specific project, and to keep from the universal requirements only the part that provides improvement of the project execution. The more voluminous is the standard, the more difficult is to do this. All development stakeholders should understand that strict formal compliance with the standard does not guarantee the quality of the results. Formal application of standards in many cases can cause harm to the development. At the same time, it should be noted that smart use of standards is a good tool to introduce in the development advanced methods and techniques. 
Along with the development of new methods and standards, market is flooded with offers to train acquiring these methods at various levels. It is obvious that the learning of new methods is partly connected with understanding and learning the new terminology which takes a great part of these courses.

Similar problems are in usage of testing standards. The testing process must be documented, otherwise we cannot prove that the program has been tested. Testing traditionally is the last development activity, and thus collects all the accumulated development time delay that "eats" the time for testing. Preparation and maintenance of testing documentation also requires additional time, so it is essential to choose the testing documentation that fit to the purposes of particular case. This was focused on by Cem Kaner speaking of previous testing documentation standards (WEB (f), 1998). Even more these requirements increase with introduction of the new version of testing standards.

In testing we can also see a growing increase in number of definitions and terms. The terms were not defined in the previous testing standard Std 829; it used a reference to the standard dictionaries. In the new standard 29 types of testing are defined. Analysing different terminological dictionaries, testing literature, testing sites and other internet sources, according to the situation on the 2015th we managed to find more than 70 definitions of different kinds of testing. It is not always clear why the specific terms are included or not included in the standard. For example, maintainability testing and safety testing definitions are included in the standard, but usability testing which is related to similar quality characteristic is not.

A large variety of terms can be found also in terms of software product quality. In literature dedicated to software quality models, before their inclusion in standards almost 90 different words have been used as software quality indicators (Cevere and Sproge, 2015). In the first version of ISO 9126 series standard 6 characteristics and 27 sub characteristics were selected from these terms (Fig 1).

\begin{tabular}{|c|c|c|c|c|c|}
\hline & & & $\begin{array}{l}\text { Internal and } \\
\text { external } \\
\text { quality model }\end{array}$ & & \\
\hline Functionality & Reliability & Usability & Efficiency & Maintainability & Portability \\
\hline $\begin{array}{l}\text { Suitability } \\
\text { Accuracy } \\
\text { Interoperability } \\
\text { Security } \\
\text { Functionality } \\
\text { compliance }\end{array}$ & $\begin{array}{l}\text { Maturity } \\
\text { Fault tolerance } \\
\text { Recoverability } \\
\text { Reliability } \\
\text { compliance }\end{array}$ & $\begin{array}{l}\text { Understandability } \\
\text { Learnability } \\
\text { Operability } \\
\text { Attractiveness } \\
\text { Usability } \\
\text { compliance }\end{array}$ & $\begin{array}{l}\text { Time behaviour } \\
\text { Resource } \\
\text { utilisation } \\
\text { Efficiency } \\
\text { compliance }\end{array}$ & $\begin{array}{l}\text { Analyzability } \\
\text { Changeability } \\
\text { Stability } \\
\text { Testability } \\
\text { Maintainability } \\
\text { compliance }\end{array}$ & $\begin{array}{l}\text { Adaptability } \\
\text { Installability } \\
\text { Co-existence } \\
\text { Replaceability } \\
\text { Portability } \\
\text { compliance }\end{array}$ \\
\hline
\end{tabular}

Fig. 1. Software product quality model in Std 9126 (ISO/IEC 9126-1).

In the new SQuaRE series standards the model of internal and external quality is extended to 8 characteristics and 31 sub characteristic (Fig 2).

Experience shows that the same quality model and the same characteristics (words) are not appropriate for software quality description in all cases and for all stakeholders.

From the end user's perspective SQuaRE simply offers a greater number of terms for quality description which, however, does not guarantee a universal application. 
A variety of classification and ranking of attributes is also seen. For example, in standard ISO 9126 Security is classified as sub characteristic of Functionality, while in SQuaRE standards Security is one of eight characteristics with several sub characteristics.

Quality standards evolution also proves that to find the universal quality model for all software cases are practically impossible.

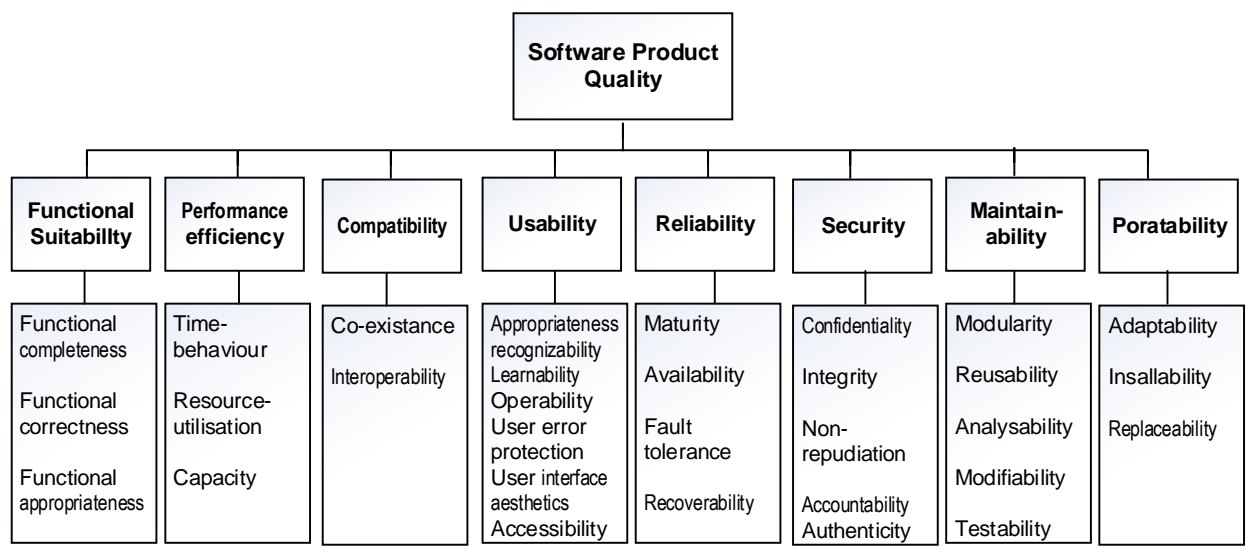

Fig. 2. Software product quality model in SQuaRE (ISO/IEC 25010)

In software development projects the situations may appear when customers for quality assurance purposes ask to audit the compliance with the standards. Usually during the audit usage of formal standard terms and headings in the delivered documents are controlled. Such situation occurs due to customers' and auditors' lack of understanding the tailoring of software engineering standards. It requires special skills of developers to be able to argue compliance with standards by nature. In order to avoid similar audit risks the auditing procedures should be developed stating the qualification of auditors. A good example is TickIt certified auditors for ISO 9000 quality system's auditing in field of information technology.

Without denying the importance of industry standards, a negative trend should be noted, which is currently observed in the development of standards. New versions of main software engineering standards appear, in which together with the development of new ideas a significant growth of total size can be seen. Of course, new useful information has been added, but in a situation when size of already existing rules and recommendations is incredibly large, it causes the objections from the professionals. A concrete example is related to ISO/IEC/ IEEE 29119 new version. Standards are discussed and agreed upon a wide circle of the involved professionals, but this time unusual reaction to the ISO/IEC/ IEEE 29119 has emerged. In petition addressed to the ISO President complaints like "the standards 'movement' is politicized and driven by big business to the exclusion of others; the methods advocated haven't been tried and the standards do not emerge from practice; the standards require users to create too much documentation; the existence of these standards forces testers to start using them; and the Testing Standards are simply another way of making money through certification" were raised (WEB, c). 
A similar situation is also in the area of legislation that affects the development of ICT industry. The adoption of certain legislative acts may adversely affect the development of information systems and scientific research. At the recent past the adoption of European regulation on the protection of personal data was an actuality in the ICT field, against the adoption of which a petition was organized by The European Data in Health Research Alliance (http://www.datasaveslives.eu/). On April 142016 the European Parliament voted for the adoption of the EU Data Protection Regulation. The final text is a great result for European health and research, striking a balance between protecting privacy and keeping research safe. The European Data in Health Research Alliance will work hard to ensure it would be implemented effectively across Europe by 2018.

The authors of the petition pay attention to the dangers of limiting scientific research in the medical and social sciences. Such a regulation will also negatively affect a variety of other information systems.

\section{Conclusions and recommendations}

Area of Information and Communication technologies is developing so fast that the technology and techniques that is advanced today can be outdated in a year or two. Information technology professionals are continually learning throughout their working lives. Therefore, one of the main requirements to young professionals by ICT companies is initiative and ability to learn. It means that in education of information technology specialists' knowledge acquisition of special subjects and learning how this knowledge constantly can be improved are equally important things.

To provide this a framework should be defined for ensuring the sustainability of professional knowledge in information technology. One of the possible decisions is to base teaching and learning processes on four milestones. The first step is to understand the requirements of the software to be developed. It means to find an answer to the question "what to do?" System analysis and modelling are an example of methods of requirements identification, and requirements specification, user stories, business needs, and prototypes are possible forms of their documentation.

The second step is to invent how the requirements will be implemented in the program. It means to find an answer to the question "how to do?". Again, a lot of methods and tools can be used for development of the design, and a lot of forms for its documentation.

The third step is implementation (coding and testing), and the last one is operation, which starts after delivery and is supported by maintenance. All these milestones are connected by organizational processes, which together form the software life cycle.

New techniques, tools and methods should be taught and learned mainly as different forms of implementation of these basic steps. For each innovation the essential new contribution should be highlighted preferably, not focusing exclusively on the learning a new terminology.

Such an approach would lay the basis for sustainable education of information technology.

The information technology industry cannot exist without education authorities, which should work in close contact with industry and research institutions. Industry associations and other organizational structures have an important role in mutual 
cooperation and exchange of information. Primary importance of them concentrates in co-operation, information exchange and coordination both within industry and through its external links.

Cooperation with legislative bodies and support to introduction of innovative ideas into production are very significant. The scope of information that is related to the industry methodologies, techniques, standards and regulatory legislation is so huge that without the participation of such subsidiary bodies it becomes difficult to manage it.

At the same time the establishment of too large number and diversity of associations and other public organizations would create a risk, because it may threaten communication with each other.

As shown in publications reviewed in this paper, need for international discussions about positive and negative effects of ICT on the sustainability become more important with each passing day. More common issues in these discussions up to now reflect the mutual relationships from different viewpoints. Up to now more frequently the following issues are discussed.

1) Information technology as necessary tools for sustainable development in all sectors.

2) ICT and the internet as a new stage of humanity in the information exchange.

3) Requirements for ICT sustainability.

4) Inclusion of sustainability in software product quality characteristics.

5) Quality characteristics of internet and their evaluation, including assessment of sustainability impact.

6) Threats to the environment generated by the ICT product development and use ("Green IT" development).

7) ICT role in education.

8) Threat distribution with the help of IT tools.

From viewpoint of information technology the main task is not only together to ensure the rapid and extensive development, but also to ensure the sustainability of information technology itself.

In the ICT sector the sustainability problems which should be addressed as one of the near-term topicality, are lack of a common framework on the basis of which to present evolution of software development methods and tools, and development of internationally harmonized ICT legislative and regulatory base. Until now, these issues have not been discussed sufficiently.

\section{References}

Akoh B., Egede-Nissen B., Creech H. (2012). Toolkit on Internet Public Policy Dialogue: Tools for the Practitioner. IISD, Winnipeg, Canada, available at http://www.iisd.org/pdf/2012/iisd_toolkit_internet_public_policy.pdf

Al-Khouri A.M. (2013). Exploring the Role of Technology in a Joined up Government: A Proposed Framework for National- Level Service Governance. International Journal of Electronic Governance and Research. Vol 2, Issue 2, February 2013, pp. 196-204.

Calero C., Moraga M.A., Bertod M.F. (20133). Towardsa software Product sustainability model. University of Malaga, available at https://arxiv.org/ftp/arxiv/papers/1309/1309.1640.pdf

Cevere R., Sproge S. (2015). Single quality model in software life cycle. WSEAS Transactions on Advances in Engineering Education. Volume 12, pp. 19-30. 
Dutta S., Geiger T., Lanvin B. (Eds.) (2015). The Global Information Technology Report 2015. ICT for Inclusive Growth. World Economic Forum, Geneva, available at http://www3.weforum.org/docs/WEF_Global_IT_Report_2015.pdf

Finnegan S., Cyr L. (2012) Moving Beyond the Tool: ICT in the Sustainable Development. Discussion at Rio+20. IISD, Winnipeg, Canada . 76-81, available at https://www.iisd.org/pdf/2012/changing_our_understanding_of_sustainability.pdf

ISO/IEC 25010. Systems and software engineering -- Systems and software Quality Requirements and Evaluation (SQuaRE) -- System and software quality models.

ISO/IEC 9126-1:2001. Software engineering - Product quality - Part 1: Quality model.

Kestemont B, Hecq W. (1996). Information technology tools for sustainable development. Presented at IATAFI 96, October 8 - 10, 1996, Brussels Congress Centre, available at http://www.ulb.ac.be/ceese/PAPERS/IATAFI/iatafi.htm

Khan H. A. Sustainable Development and Information Technology. Available at http://www.sciencevision.org.pk/BackIssues/Vol7/Vol7No1-2/Vol7No1\&2_2_Sustainable _Development_IT_HameedAKhan.pdf

MacLean D. (2013). Sustainable Communication, available at https://www.opencanada.org/features/sustainable-communication/

MacLean D., Souter D., Creech H. (2012). ICT, the Internet and Sustainability: A discussion guide for Rio+20. IISD, Winnipeg, Canada . 64-68, available at https://www.iisd.org/pdf/2012/changing_our_understanding_of_sustainability.pdf

Mahaux M., Canon C. (2012). Integrating the complexity of sustainability in requirements engineering, available at http://sustainability.wiki.tum.de/file/view/integrating+the+complexity+of+sustainability+in+ requirements+engineering.pdf

Mahaux M., Heymans, P.Saval G. (2012). Discovering Sustainability Requirements: An Experience Report. University of Namur, Belgium, available at https://staff.info.unamur.be/mma/wordpress/wp-content/uploads/2012/02/paperExpReport. pdf

Mansell R. (2012). ICT Innovation and Sustainable Development. IISD COMMENTARY. IISD, Winnipeg, Canada. 43-48, available at https://www.iisd.org/pdf/2012/changing_our_understanding of_sustainability.pdf

Mansell R., Tremblay G. (2013). Renewing the Knowledge Societies Vision for Peace and Sustainable Development. UNESCO, available at http://unesdoc.unesco.org/images/0022/002245/224531E.pdf

Mobbs P. (2012). A practical guide to sustainable information technology. (APC), South Africa, available at http://www.apc.org/en/pubs/practical-guide-sustainable-it

Paas L. (2008). How Information and Communications Technologies Can Support Education for Sustainable Development. Current uses and trends, available at https://www.iisd.org/sites/default/files/publications/ict_education_sd_trends.pdf

Penlington R., Steiner S. (2010). An Introduction to Sustainable Development in the Engineering Curriculum. Higher Education Academy. Engineering Subject Centre. Available at https://www.heacademy.ac.uk/sites/default/files/introduction-to-sustainabledevelopment.pdf

Penzenstadler B. (2016). Infusing Green: Requirements Engineering for Green In and Through Software Systems. University of California, available at http://ceur-ws.org/Vol-1216/paper8.pdf

Penzenstadler B. (2013). What does sustainability mean in and for software engineering? (ICT4S). Available at https://www.researchgate.net/publication/255949741 What does Sustainability mean in a nd_for_Software_Engineering

Penzenstadler B. (2015). A Toolkit for SE for Sustainability - A Design Fiction, available at http://web.csulb.edu/ bpenzens/pdf/AToolkitForSE4S.pdf 
Penzenstadler B. Supporting sustainability aspects in software engineering. Institut fur Informatik, Technische Universitat Munchen, Germany. Available at http://www.computational-sustainability.org/compsust12/papers/24.pdf

Penzenstadler B., Femmer H. (2013). RE@21: Time to sustain! Available at http://ceur-ws.org/Vol-995/paper1.pdf

Penzenstadler B., Khurum M., Peterson K. (2013). Towards incorporating sustainability while taking software product management decisions. University of Duisburg-Essen , IWSPM. Available at http://www.diva-portal.org/smash/get/diva2:834513/FULLTEXT01.pdf

Penzenstadler B., Tomlinson B., Richardson D. (2011). RE4E: support environmental sustainability by requirements engineering. University of California. Available at htpps://sustainability.wiki.tum.de/file/view/preview_EnviroSiSE_Penzenstadler_re4susy.pdf

Raghupathi W., S. Wu. (2013). The Strategic Association between Information and Communication Technologies and Sustainability Development Indicators: A Country-Level Study. Fordham University, available at http://www.fordhamcdt.org/pdf/ICT-and-Sustainability.pdf

Rivera A.C., Kurnia S. (2015). Exploring the roles of ICT in supporting sustainability practices. Australasian Conference on Information Systems. 1-10, available at https://acis2015.unisa.edu.au/wp-content/uploads/2015/11/ACIS_2015_paper_50.pdf

Rober K., Richardson D. (2013). Sustainability requirement patterns. University of California. 311 , available at http://www.ics.uci.edu/ kroher/Kristin_Roher/Home_files/rews13repa-id6-p-18156preprint.pdf

Rogers-Estable M. (2011). Technology \& Sustainable Development. How online tools can educate. ISSP, available at https://www.sustainabilityprofessionals.org/system/files/Technology_and_ESD.pdf

Ryan C.D., Creech H. (2008). An Experiment with Social Network Analysis: Assessing the scope and scale of IISD's relationships on Internet governance as a test of the usefulness of social network analysis for network evaluation. IISD, Winnipeg, Canada, available at http://www.iisd.org/pdf/2012/social network analysis.pdf

Saval G., Mahaux M., Heymans P. (2013). Paper of „Discovering Sustainability Requirements: An Experience Report", Faculty of Science, Utrecht University, available at http://foswiki.cs.uu.nl/foswiki/MethodEngineering/DiscoveringSustainabilityReq20122013

Souter D. (2012). ICT, the Internet and sustainability: a discussion paper. IISD. Winnipeg, Canada $3-25$, available at https://www.iisd.org/pdf/2012/changing_our_understanding_of_sustainability.pdf

Souter D., MacLean D. (2012). ICT, the Internet and Sustainability: Where Next? IISD REPORT, IISD, Winnipeg, Canada. 135-161, available at https://www.iisd.org/pdf/2012/changing_our_understanding_of_sustainability.pdf

Souter D., MacLean D. (Eds) (2012). Changing our understanding of sustainability. The impact of ICT and the Internet. IISD. Winnipeg, Canada, available at https://www.iisd.org/pdf/2012/changing_our_understanding_of_sustainability.pdf

Souter D., MacLean D., Okoh B., Creech H. (2010). ICT, the Internet and Sustainable Development: Towards a new paradigm, available at https://www.iisd.org/pdf/2010/ICT_internet_sd_new_paradigm.pdf

Souter D., MacLean, Creech H. (2013). Towards Knowledge Societies for Peace and Sustainable Development, available at https://ICTtheinternetandsustainability.wordpress.com/2013/02/27/towards-knowledgesocieties-for-peace-and-sustainable-development-3/

St. Arnaud B. (2012). Using ICT for Adaptation Rather Than Mitigation to Climate Change. IISD COMMENTARY. IISD, Winnipeg, Canada. 49-55, available at https://www.iisd.org/pdf/2012/changing_our_understanding_of_sustainability.pdf 
Vickery G. (2012). Smarter and Greener? Information Technology and the Environment: Positive or negative impacts? IISD, Winnipeg, Canada. 57-62, available at https://www.iisd.org/pdf/2012/changing_our_understanding_of_sustainability.pdf

WEB (a) (2009). Guide to Measuring Information and Communication Technologies (ICT) in Education. UNESCO Institute for Statistics. https://www.itu.int/ITU-D/ict/partnership/material/ICT_Guide_EN.pdf

WEB (b) (2009). Measuring the Relationship between ICT and the Environment. OECD, http://www.oecd.org/sti/43539507.pdf

WEB (c) (2014). Response to Stop 29119 Petition. http://www.softwaretestingstandard.org/29119petitionresponse.php

WEB (d) (2014). Sustainability Competences for Engineers. . The Royal Academy of Engineering. http://www.raeng.org.uk/publications/other/sustainability-workshop

WEB (e) (2015). The Internet and Sustainable Development. Internet Society, http://www.internetsociety.org/doc/internet-and-sustainable-development

WEB (f) (1998). Requirements for Test Documentation. http://kaner.com/pdfs/QaiRequirements.pdf

Received June 22, 2016, revised December 16, 2016, accepted January 2, 2017 